\title{
Influence of Selected Social Factors on Students' Attitude towards Chemistry
}

\section{Jonah Mokoro Mokoro}

\author{
St Joseph's Etono Secondary School, Nyamira, Kenya
}

\author{
Dr. Pascal Wambiya \\ Coordinator for Academic Programmes, The Catholic University of Eastern Africa (CUEA), \\ P.O. BOX 62157, 00200, Nairobi, Kenya \\ Email: pwambiya@cuea.edu \\ Dr Peter J.O. Aloka
}

Jaramogi Oginga Odinga University of Science and Technology, Kenya

\section{Doi:10.5901/mjss.2014.v5n20p1772}

\section{Abstract}

The study investigated the influence of selected social factors influencing the students' attitude towards Chemistry in Nyamaiya division, Nyamira county, Kenya. The study adopted an ex-post facto design and the target population comprised all secondary school students in Nyamaiya division. Simple random sampling will be used to select 300 respondents from a total population of 2890 secondary school students. Questionnaires were used to collect data. Data was analyzed by inferential techniques such as Pearson Product Moment Correlation Coefficient. The hypotheses were tested at $\alpha=0.05$ significance level. The findings revealed that there was a statistically significant influence between the teacher's characteristics and the students' attitude towards Chemistry. However, students' career interest and peers had no influence on the students' attitudes towards chemistry. The Ministry of Education should develop in - service programmes and refresher courses for teachers that emphasize the need to adopt creative and motivating methods of teaching and the importance of being available to the students. This will in turn help students develop positive attitude which in turn leads to better academic achievement.

Keywords: teacher characteristics, peer influence, career interests, Students, Attitude, Chemistry, secondary, schools

\section{Introduction}

'Education and training systems that responds adequately to these demands will therefore, contribute to the efforts to overcome the growing unemployment and marginalization of majority of the population. Providing access to appropriate learning experiences, designed to broaden skills and knowledge can increase productivity and significantly improve the fortunes of the unemployed, thereby reducing poverty and unemployment amongst the youth (Adesoji, 2008). It is as a result of the recognition given to Chemistry in the development of the individual and the nation that it has been made a core pre-requisite subject for offering most science oriented courses in the tertiary institutions and this calls for the need in teaching it effectively. The teaching of Chemistry is supposed to be result oriented and students centred, and this can only be achieved when students are willing and the teachers are favourably disposed, using the appropriate methods and resources in teaching the students. Students by nature are curious; they need to be actively involved in the learning process in which they are continuously equipping, testing, speculating and building their own personal construct and knowledge. It is only by personalizing such knowledge that it becomes valid, meaningful and useful to them. In Chemistry, students need to actively construct their own personal awareness and meaning (Usman, 2000). To achieve this, it is important to encourage the development of positive attitudes towards chemistry.

Attitude is a hypothetical construct that indicates an individual's like or dislike towards an item. It may be positive, negative or neutral. Attitude is an approach, temperament, sensation, situation, etc. with regard to a person or thing. It is an inclination or course, especially of the mind. Attitude is a way of looking at things (Muellerleile, 2005). There is no consensus among researchers on the meaning of attitude because attitude is a multi-faceted construct. Different researchers define attitude differently. Oskamp and Schultz (2005) described that there are three major theoretical viewpoints about the important nature of attitudes that have been proposed by social psychologists; the tri-component 
point of view, the separate entities point of view, and the latent process perspective. The tri-component point of view forwards affect, behaviour, and cognition as the three components of attitude which is a single entity. The thoughts and emotions one has toward an attitude object such as Chemistry lessons and Chemistry subject are referred to as the affective component of attitude. The individual's explicit events and reactions to the attitude object is referred to as the behaviour component of attitude, while the cognitive component is the thinking or belief that someone has about the attitude object. The second theoretical point of view about the nature of attitudes, presents the three components that is; affect, behaviour and cognition as unique and separate entities, this view assumes that the term attitude refers to the affective component only. Cognition and behaviour are considered as determinants instead of components of an attitude. This point of view has been described by investigators such as Thurstone (1931) and Fishbein and Aizen (1975). They have described attitude as the sum of affect for or in opposition to an object. The third theoretical point of view, forwards attitude as a latent variable that can explain the connection between certain observable stimulus events and behaviours. Attitudes can be formed from cognitive, affective, and/or behavioural information about the attitude objects and expressed through cognitive, affective, and/or behavioural responses. According to Oskamp and Schultz (2005), the latent process viewpoint is better than the tri-component viewpoint or the separate entities viewpoint because it is more consistent with findings of contemporary attitude research. In this present study, the researcher will use Oskamp and Schultz's (2005) definition of attitude (i.e., an attitude is a tendency to react in a positive or negative style with respect to a given attitude object) and based on the latent process point of view students attitude towards Chemistry will be measured. It is worth mentioning that the development of the students' positive attitude is necessary because attitude is linked with academic achievement (Cheung, 2009). Similarly, a study conducted by Kelly (1998) concluded that the British students' liking for a specific science subject were the actual predictor of their choice in school in various subjects. Therefore, all stakeholders should consider the development of positive attitude towards the chemistry subject as one of their central responsibilities (Cheung, 2009).

Poor performance in chemistry has persistently remained a concern in Nyamira district, Kenya. Previous research has been done to investigate the factors that affect students' performance in chemistry, but the primary focus has been on academic skills. However, recent research suggest that students' achievement also depend on academic enablers such as attitudes and behaviours that allow them to participate in and ultimately benefit from the academic instruction in the classroom. Student attitudes play a central role in the learning and achievement in chemistry. Positive attitudes form the basis for optimism. For students, optimism can present itself as persistence. If failure is experienced an optimistic student is more likely to rationalize the event. Instead of becoming depressed and helpless, the student, if optimistic, is more likely to demonstrate resilience and try again. Through persistence, optimistic students are more likely to remain engaged in learning episodes and this engagement will assist in achievement. In contrast, negative attitudes can enhance chemistry-anxiety and consequently negatively affect academic achievement in chemistry. In Kenya, the negative attitudes held by students towards Chemistry has among other factors, been blamed for the persistent below average performance in chemistry. Even though students' attitude towards science has been extensively studied, previous research has focused greatly on science in general and less attention has been addressed to particular disciplines like chemistry. Hence, this study sought to establish the influence of social factors on the students' attitude towards chemistry.

\section{Theoretical Framework and Literature Review}

\subsection{Theoretical Framework}

This study was informed by the social learning theory. Social learning focuses on the learning that occurs within a social context. It considers how people learn from one another, encompassing such concepts as observational learning, imitation and modelling (McLeod, 2011). Social learning emphasizes the value of observing and modelling behaviours, attitudes and emotional reactions of others. The theory informs the study in that, students bring to any learning situation a unique set of mental constructs, a fluctuating emotional state of being, and most importantly, a personal sense of selfefficacy, or feeling of capability and likelihood to succeed. These factors then interact with the habitual behavioural patterns of the individual, such as procrastination or organization, and the environmental factors, such as the nature of the task, the social and physical environment, the modelling and reinforcement received by the individual to determine the behaviour and attitudes that the individual will develop. Self-efficacy, derived from Bandura's social learning theory, is the belief in one's ability to perform the behaviours required to produce a desired outcome and is considered to be an important determinant of behaviour change (Bandura, 1986).

Among the main weakness of the theory is that it does not stress the child's actual cognitive development. While 
there are some cognitive insights in Social Learning Theory, this is not stressed (Johnson, 2012). A child is seen as a sponge, absorbing information through modelling. The actual child's contribution to how such models are absorbed, processed and worked out through time is not present to any great extent in the theory. The other weakness of Social Learning Theory is innovation. Social Learning Theory is a theory based on imitation via observation. It does not stress what happens later-innovation. While the initial blueprint for activity is seen in the model (the expert who is observed) can easily be visualized, there seems to be no model for innovation. Innovation is too abstract to be modelled (Johnson, 2012).

\subsection{Review of literature}

Several previous studies have been carried out on teachers' characteristics and its influence on students' academic achievement. For example, Adesoji (2008) investigated whether the attitude towards problem solving in chemistry would change when students are exposed to different teaching methods in Osun State of Nigeria. The result showed that there was no significant difference in the attitude of the three groups towards solving problems on electrolysis before the treatment. The findings of the above study have established the fact that acceptable methods of instruction are capable of changing students' attitude towards chemistry. Kususanto, Fui and Hooi (2012) studied whether the teachers' expectancy influenced students' attitude towards science. The results indicated that the teacher's expectancy significantly affected students' attitude towards science and that different kind of expectancy led teachers to have different classroom behaviour. Similarly, Olusola \& Rotimi (2012) investigated attitudes of students towards the study of physics in college of education Ikere-Ekiti, Ekiti State, Nigeria. The findings of this study established that students held high favourable attitudes towards physics. The findings suggested that good lecturer -student interrelationships led to the development of positive attitudes towards physics courses among the students. Barchok, Too, \& Ngeno (2013), studied the effect of collaborative concept mapping teaching strategy on students' attitudes towards chemistry in selected secondary schools in Bomet district, Kenya. The results suggested that CCM as a teaching strategy had no significant effect on development of ATC among students in experimental groups. Kosgei, Mise, Odera \& Ayugi (2013), studied the influence of teacher characteristics on student academic attitudes and achievement, in selected secondary schools in Nandi South District, Kenya. The results revealed that as the level of education increased, the student performance and positive attitudes also increased. The result implied that teacher academic qualification influenced student's academic attitude and achievement.

Other previous studies have also investigated the Student's Career Interest on Students' Attitude towards Chemistry. For example, Kan, Akba (2006), determined students' level of attitude and self efficacy towards chemistry among male and female students and to put forth effects of these variables on chemistry achievement for consideration in Mersin city, Turkey. The study found that there were no significant differences between the mean of attitude score according to gender. Prokop, Tuncer \& Chudá (2007) investigated the influence of career interest on Slovakian students' attitudes toward Biology. A univariate ANOVA showed that student' attitudes toward biology have been significantly affected by students' career preferences. Jegede (2007) investigated the Students' anxiety towards the learning of Chemistry in some Nigerian secondary schools. The results showed that $97 \%$ of the students held the popular notion that the subject is too wide, demanding and rather cumber some; about $96 \%$ of them feared chemistry because it demands too much of calculation while $95 \%$ were of the opinion that it is difficult to understand chemical equation and arithmetic. About $94 \%$ revealed that there were more failures in Chemistry examinations than passes. Udoukpong, Emah \& Umoren (2012), studied the difference in junior secondary students' academic performance in Entrepreneurial Curriculum of Business Studies based on their attitudes to the subject, parental influence, and career aspirations. The t-test analysis showed a significant difference in the students' academic achievement and attitudes towards Business Studies based on parental influence. Woldeamanuel, Atagana \& Engida (2013) studied the students' anxiety towards the learning of chemistry in some Ethiopian universities. The results showed that students in rural areas registered more fear in learning chemistry than their counterparts in urban area. Students in the rural areas are scared by (in descending order) job opportunities, wide coverage of the syllabus, lack of exposure, teacher's qualities and methodology and more failures than passes.

Other previous studies have also investigated the Peer Influence on Students' Attitude towards Chemistry. For example, Etherington (2008) studied how girls' achievements in school art are undermined by boys' rejection of the subject in the UK and found that boys more than girls viewed art as irrelevant to their future lives and careers. Majeed (2010) investigated peer group effects on academic achievement of government girls' high school Khyaban-e-Sir Syed Rawalpindi and found that most of the respondents agreed that friendship played an important part in their studies. Further, most of the students agreed that interest in studies may develop more on seeing their friend's effort on studies 
and they took interest in knowing about their friend's completion of work in studies. Mukama (2010) studied the relationship between peer group influence and secondary school students' attitudes towards school in secondary schools in Mbarara District, Uganda. The findings of the study indicated that there was no significant relationship between peer group influence and students' attitudes towards school. The results further indicated that there was no significant relationship between peer group influence and alcohol consumption. Mukala (2012) investigated peer versus parental conformity among adolescents in secondary schools in Kitui district, Kenya and reported that adolescents conformed more to their parents on issues such as personal grooming, leisure, education, discipline and religion than they conformed to their peers. Breakwell (2012) studied how gender, parental and peer influences affect science attitudes and activities in the UK and reported that boys had more positive attitudes to science and greater levels of participation in scientific extra-curricular activities. Okorodudu (2013) investigated peer pressure and socioeconomic status as predictors of student's attitude to examination malpractice in Nigeria and found out that there existed a significant relationship between peer pressure and students' attitude to examination malpractice. The results further suggested the peer pressure is one of the major factors that enhance examination malpractice behaviour among students. Finally, Lam (2012) reported that friends and study mates were endogenously formed which led to overestimation of peer effects in traditional exogenous peer formation models.

From the review of literature review, most previous studies have been done based on the western contexts and other African countries, and very scanty literature was available regarding Kenyan context. Moreover, in some studies, the researcher focussed on the teaching methods only, in the current study, the researcher studied other aspects of the teacher; for example, teacher motivation, and the teacher's expectation and their effect on the students' attitude towards chemistry. In addition, some studies have adopted a qualitative approach, while the current study filled this gap by using the quantitative approach.

The following hypotheses were tested:

Ho1: There is no statistically significant relationship between the teacher's characteristics and the students' attitude towards Chemistry in Nyamaiya division, Nyamira district, Kenya.

Ho2: There is no statistically significant relationship between the student's career interest and the students' attitude towards Chemistry in Nyamaiya division, Nyamira county, Kenya.

Ho3: There is no statistically significant relationship between peer influences and the students' attitude towards Chemistry in Nyamaiya division, Nyamira county, Kenya

\section{Research Methodology}

\subsection{Research design}

This research adopted a survey using ex-post facto research design. The ex-post facto design is a systematic, empirical research, in which the researcher does not have direct control over the independent variables because their manifestations have already occurred (Kerlinger, 2000). The independent variables in this study, is teacher characteristics, peer influence and career interests are already manifested in the respondents and therefore, cannot be manipulated by the researcher. Likewise, the dependent variable, that is, the students' attitude towards Chemistry, has already developed and the researcher has no control over it.

\subsection{Study participants}

The target population of this study were students in all secondary schools in Nyamaiya division of Nyamira county, Kenya. According to the Nyamira District Education Officer's (DEO) records for the year 2013, the division has 15 secondary schools. The target population comprises 2890 students. Data was collected from all the 15 secondary schools in the division. In order to get the sample size, the researcher used Mugenda and Mugenda (2003) thumb rule of $10 \%$ of the target population. The $10 \%$ of the target population of 2890 respondents made a sample size of 300 respondents. Simple random sampling was used to select 20 students from the form three classes from each of the 15 schools to get the required sample.

\subsection{Research instruments}

The researcher used questionnaires to collect data. The first student questionnaire addressed the independent variable, that is, parental influence with a 4-point likert scale. The second student questionnaire addressed the students' attitude 
towards chemistry. The validity of the questionnaires was ensured by using university lecturers, as indicated by Borg and Gall (1989) that content validity of an instrument is improved through expert judgment. Reliability of the questionnaires was ensured by using the Split-Half technique, whereby the pilot questionnaires were divided into two equivalent halves and then a correlation coefficient for the two halves computed using the Spearman Brown Prophesy formula. The coefficient indicates the degree to which the two halves of the test provide the same results. The correlation coefficient of 0.7 obtained recommended as indicating that an instrument is reliable (Wells \& Wollack, 2003).

\subsection{Data collection procedures}

Permission to carry out the study was first obtained from Laikipia university Kenya and then two approved copies of research proposal were forwarded to the Ministry of Education Kenya for issuance of research permit. The researcher duly informed the respondents in the study that their participation was voluntary and that they were free to omit answers to any particular questions if they so chose. The researcher also protected their confidentiality and identity through use of numbers in line with recommended procedures that the participants should remain anonymous throughout the study.

\subsection{Data Analysis}

Quantitative data was collected from the 300 students from the 15 secondary schools in Nyamaiya division of Nyamira county using a questionnaire. The quantitative data was analysed using the Statistical Package for Social Sciences (SPSS) version 20. Positive items will be scored from four to one; from strongly agree to strongly disagree, respectively, while negative items were scored in the reverse order. Descriptive statistics involved the use of means and percentages while an inferential statistical test was used to test the hypothesis. Pearson's Product Moment Correlation coefficient was used to establish the relationships between the variables. The hypotheses will be tested at $5 \%$ level of significance in determining whether to accept or reject the study hypotheses at $\alpha=0.05$ level of significance.

\section{Findings and Discussion}

\subsection{Influence of Teacher Characteristics on Students' Attitude towards Chemistry}

The first objective was to determine whether the teacher's characteristic had a statistically significant influence on the students' attitude towards Chemistry. Descriptive analysis was done on the scores on the 20 items in the teacher characteristic questionnaire and the SPSS output is shown in table 1.

Table 1: Descriptive Statistics on Teacher Characteristics

\begin{tabular}{|l|c|c|c|c|c|}
\hline & $\mathrm{N}$ & Minimum & Maximum & Mean & Std. Deviation \\
\hline Teacher characteristics & 300 & 20.00 & 80.00 & 69.7667 & 9.81121 \\
Students' Attitude & 300 & 30.00 & 120.00 & 91.8467 & 12.30126 \\
\hline
\end{tabular}

The mean score was 69.76 with a standard deviation of 9.81 as shown in table 1. This mean (69.76) implies that generally, a majority of the students held favourable attitudes towards their chemistry teachers.

To determine whether the teacher's characteristics had any statistically significant influence on the students' attitude towards Chemistry, a statistical test that is a bivariate Pearson product moment correlation coefficient was calculated. It was reported that, there was a strong positive correlation $(r=0.906)$ between students' attitude towards teacher characteristics and students' attitudes toward chemistry as shown in table 2. This means that, as the positive students' attitude towards teacher characteristics increases, secondary school students' positive attitude toward chemistry also increases. 
Table 2: Correlation between Teacher Characteristics and Students' Attitude

\begin{tabular}{|ll|c|c|}
\hline & & Teacher & Attitude \\
\hline \multirow{3}{*}{ Teacher characteristics } & Pearson Correlation & 1 & $.909^{*+}$ \\
& Sig. (2-tailed) & & .000 \\
& $N$ & 300 & 300 \\
& Pearson Correlation & $.906^{* *}$ & 1 \\
Students' Attitude & Sig. (2-tailed) & .000 & \\
& $N$ & 300 & 300 \\
\hline
\end{tabular}

Note: **. Correlation is significant at the 0.05 level (2-tailed).

When the hypothesis which stated that "There is no statistically significant influence between the teacher's characteristics and the students' attitude towards Chemistry in Nyamaiya division, Nyamira district, Kenya" was tested, the results in table 7 showed that there was a statistically significant influence between the teacher's characteristics and the students' attitude towards Chemistry $(p<0.0005)$ at 0.05 level of significance; Hence, the null hypothesis that there is no statistically significant relationship between the teacher's characteristics and the students' attitude towards chemistry in Nyamaiya division, Nyamira district, Kenya was rejected. This finding is consistent with Adesoji (2008), who found out that acceptable methods of instruction are capable of changing students' attitude towards chemistry. Similarly, Kususanto, Fui and Hooi (2012), also found out that teachers expectancy affected students' attitude towards science. Olusola and Rotimi (2012) similarly established that good lecturer-student interrelationships led to the development of positive attitudes towards physics among the students. Further, Kosgei, Mise, Odera \& Ayugi (2013) also found out that as the number of teachers' years of experience progressed, student attitude and academic achievement increased and vice versa. The implication of these findings is that teacher characteristics have a significant influence on students' attitude towards Chemistry. Therefore, teachers should be sensitised on the fact that they play an important role in influencing student attitudes towards chemistry. For example, the teachers should be sensitised on the importance of using acceptable methods of instruction that are capable of changing students' attitude towards chemistry. Similarly, teachers should be exposed to the fact that teachers' expectancy can influence students' attitude towards chemistry, and that good teacherstudent interrelationships can lead to the development of positive attitudes towards chemistry among the students.

\subsection{The Influence of Student's Career Interest on Students' Attitude towards Chemistry}

The third objective was to determine whether student's career interest had a statistically significant effect on students' attitude towards chemistry. A general inquiry was done on the percentages of responses on various statements. Descriptive analysis was done on the scores from the 20 items in the students' career interest questionnaire. The SPSS output is shown in table 3.

Table 3: Descriptive Statistics on Students' Career Interest

\begin{tabular}{|l|c|c|c|c|c|}
\hline & N & Minimum & Maximum & Mean & Std. Deviation \\
\hline Students' Career Interest & 300 & 20.00 & 80.00 & 57.88 & 9.377 \\
Attitude & 300 & 30.00 & 120.00 & 91.8467 & 12.30126 \\
& & & & & \\
\hline
\end{tabular}

From the descriptive analysis, the mean score was 57.88 points with standard deviation of 9.377 as shown in table 3 . This mean (57.88) implies that generally, a slightly more than average majority of the students held favourable career interest in chemistry. To determine whether the student's career interest had any influence on the students' attitude towards Chemistry, a statistical test that is a bivariate Pearson product moment correlation coefficient was calculated. The results revealed a very low negative correlation $(r=-0.078)$ between students' career interest and student attitudes toward chemistry as shown in table 4 . This meant that there was negligible relationship between students' career interest and secondary school students' attitude toward chemistry. 
Table 4: Correlation between Students' Career Interest and Students' Attitude

\begin{tabular}{|cl|c|c|}
\hline & Attitudes & Career \\
\hline \multirow{3}{*}{ Attitudes } & Pearson Correlation & 1 & -.078 \\
& Sig. (2-tailed) & & .179 \\
& $N$ & 300 & 300 \\
& Pearson Correlation & -.078 & 1 \\
& Sig. (2-tailed) & .179 & \\
& $\mathrm{~N}$ & 300 & 300 \\
\hline
\end{tabular}

When the hypothesis which stated that 'There is no statistically significant influence between the students' career interest and the students' attitude towards Chemistry in Nyamaiya division, Nyamira district, Kenya" was tested, it was found to be non significant $(\mathrm{p}=0.179)$ at 0.05 level of significance; that is there was no statistically significant relationship between the students' career interest and the students' attitude towards Chemistry in Nyamaiya division, Nyamira district, Kenya. Hence, the null hypothesis that there is no statistically significant relationship between the students' career interest and the students' attitude towards Chemistry in Nyamaiya division, Nyamira district, Kenya was not rejected. The findings therefore, revealed that the student's career interest had no statistically significant influence on the student attitudes towards chemistry.

This finding collaborate with Udoukpong, Emah \& Umoren (2012), who showed that there was no significant difference in the academic achievement and attitudes towards Business Studies of junior secondary students based on students' career aspirations. This finding is also consistent with Waihenya (2013), who established that failure by students to choose agricultural careers is neither as a result of poor academic performance in the subject nor by attitudes held by students towards agriculture as a subject. However, this finding contradicts Prokop, Tuncer \& Chudá (2007), who found out that student' attitudes toward Biology have been significantly affected by students' career preferences. The difference in the findings would have arisen because the study was done in Slovakia and focussed on biology while the current study was done in Kenya and in chemistry. Hence, the difference in the findings would have been as a result of differences in culture, society and parental expectations. The implication of these findings is that the student's career interest had no statistically significant influence on the students' attitude towards chemistry in Nyamaiya division, Nyamira district, Kenya. Therefore, the career guidance teachers should be sensitized on the importance of explaining the relationship between careers and subject choices so as to help the students realise the bridge between a subject and a career. The school administration and the guidance and counselling department should also be sensitised on the need to invite professionals and resource persons to make presentations to the students to further reinforce the importance of subject choice and performance on future careers.

\subsection{The Effect of Peer Influence on Students' Attitude towards Chemistry}

The fourth objective was to determine whether peer influence had a statistically significant effect on students' attitude towards chemistry. Descriptive analysis was done on the scores on the 10 items in the peer influence questionnaire. The SPSS output is shown in table 5.

Table 5: Descriptive Statistics on Peer Influence

\begin{tabular}{|l|c|c|c|c|c|}
\hline & $\mathrm{N}$ & Minimum & Maximum & Mean & Std. Deviation \\
\hline Peer Influence & 300 & 10.00 & 40.00 & 20.93 & 6.347 \\
Attitude & 300 & 30.00 & 120.00 & 91.8467 & 12.30126 \\
\hline
\end{tabular}

From the descriptive analysis, the mean score was 20.93 with standard deviation of 6.347 as shown in table 5 . This mean (20.93) implies that about half of the students said that they were influenced by their peers in making decisions concerning chemistry. To determine whether peer influence had any statistically significant influence on the students' attitude towards Chemistry, a statistical test that is a bivariate Pearson product moment correlation coefficient was calculated. The results revealed a very low negative correlation $(r=-0.016)$ between peer influence and student attitudes toward chemistry as shown in table 6 . This meant that there was negligible relationship between peer influence and 
secondary school students' attitude toward chemistry.

Table 6: Correlation between Peer Influence and Students' Attitude

\begin{tabular}{|ll|c|c|}
\hline & & Attitudes & Peer \\
\hline \multirow{4}{*}{ Attitudes } & Pearson Correlation & 1 & -.016 \\
& Sig. (2-tailed) & & .785 \\
& $\mathrm{~N}$ & 300 & 300 \\
& Pearson Correlation & -.016 & 1 \\
Peer & Sig. (2-tailed) & .785 & \\
& $\mathrm{~N}$ & 300 & 300 \\
\hline
\end{tabular}

When the hypothesis which stated that "There is no statistically significant influence between the students' career interest and the students' attitude towards Chemistry in Nyamaiya division, Nyamira district, Kenya" was tested, it was found to be non significant $(p=0.785)$ at 0.05 level of significance; that is there was no statistically significant relationship between peer influence and the students' attitude towards Chemistry in Nyamaiya division, Nyamira district, Kenya. Hence, the null hypothesis that there is no statistically significant relationship between peer influence and the students' attitude towards Chemistry in Nyamaiya division, Nyamira district, Kenya was not rejected. The findings therefore, revealed that peer influence had no statistically significant influence on the student attitudes towards chemistry. This finding is consistent with Mukama (2010) whose results indicated that there was no significant relationship between peer group influence and alcohol consumption. This finding also collaborate Mukala (2012) whose results revealed that adolescents conformed more to their parents on issues such as personal grooming, leisure, education, discipline and religion than they conformed to their peers. This finding could also be explained by what Hinds et al. (1999) found, that other factors like parents and teachers play a greater role in shaping students' attitudes towards school. As such, the lack of relationship between peer influence and secondary school students' attitudes towards chemistry may be attributed to teacher and parental involvement in the students' academic affairs. However, this finding contradict Breakwell (2012), who suggested that a positive attitude to science was strongly positively related to having a father and mother who support science and having scientific peers. This contradiction could have been as a result of the study being carried out in the UK and hence the findings may have differed with the findings of the current study due to variations in culture, poverty levels and parental expectations.

The implication of these findings is that peer influence had no statistically significant influence on the students' attitude towards chemistry in Nyamaiya division, Nyamira district, Kenya. Therefore, teachers should be sensitised on the importance of promoting positive peer interactions. Lindgren (1980) observed that, individuals need to relate to their peers for they are dependent on their attitudes, feelings, and expectations to help them construct their own views of the world. Farmer (2010) also affirmed that peers are not inherently positive or negative; they can be both good and bad. He further noted that, peer friendships, group interactions, and influences are a part of positive development. Black (2002) also observed that, peer groups can offer emotional benefits, such as affection, love, understanding, and support from friends and if these friends are intelligent, they might help the individual students in developing positive attitudes towards school and specific subjects like chemistry. These findings further reinforce the need for the teachers, parents, guidance and counselling teachers and school administrations to promote positive peer interactions.

To find out what proportion of students' attitude towards chemistry can be explained by the three variables investigated, a multiple regression analysis was carried out. The results are presented in table 7.

Table 7: Model Summary

\begin{tabular}{|c|c|c|c|c|c|c|c|c|c|}
\hline \multirow{2}{*}{ Model } & \multirow{2}{*}{$\mathrm{R}$} & \multirow{2}{*}{ R Square } & \multirow{2}{*}{$\begin{array}{l}\text { Adjusted R } \\
\text { Square }\end{array}$} & \multirow{2}{*}{$\begin{array}{l}\text { Std. Error of the } \\
\text { Estimate }\end{array}$} & \multicolumn{5}{|c|}{ Change Statistics } \\
\hline & & & & & R Square Change & F Change & $d f 1$ & $\mathrm{df} 2$ & Sig.F Change \\
\hline 1 & $.911^{\mathrm{a}}$ & .830 & .827 & 5.11302 & .830 & 358.919 & 3 & 295 & .000 \\
\hline
\end{tabular}

a. Predictors: (Constant), Peer, Teacher, Career

From table 7, the multiple correlation coefficient $(R=0.911)$ is the correlation between the levels students' attitude reported by the respondents and the levels students' attitude predicted for them by the independent variables; teacher characteristics, student career interest and peer influence. A value of $\mathrm{R}=0.911$ indicates a good level of prediction. The 
coefficient of determination $\left(R^{2}=0.830\right)$ indicates the proportion of the variance in the dependent variable (the students' attitude towards chemistry) which is accounted for by the model. Implying that $83 \%$ of the variability in the students' attitude towards chemistry could be explained by the four independent variables; teacher characteristics, student career interest and peer influence. The rest (17\%) could be explained by other factors not included in the study.

To find out which of the independent variables were most significant in influencing the students' attitudes towards chemistry, a multiple regression analysis was performed and the SPSS output is shown in table 8.

Table 8: Regression coefficients

Coefficients $^{\mathrm{a}}$

\begin{tabular}{|l|c|c|c|c|c|c|c|}
\hline \multirow{2}{*}{ Model } & \multicolumn{2}{|c|}{ Unstandardized Coefficients } & Standardized Coefficients & \multirow{2}{*}{$\mathrm{t}$} & \multirow{2}{*}{ Sig. } & \multicolumn{3}{|c|}{$95.0 \%$ Confidence Interval for B } \\
\cline { 2 - 4 } & $\mathrm{B}$ & Std. Error & Beta & & & Lower Bound & Upper Bound \\
\hline (Constant) & 9.316 & 3.459 & & 2.693 & .007 & 2.509 & 16.123 \\
Teacher & 1.058 & .037 & .844 & 28.681 & .000 & .985 & 1.130 \\
Career & -.005 & .033 & -.004 & -.154 & .878 & -.069 & .059 \\
Peer & .004 & .048 & .002 & .088 & .930 & -.090 & .099 \\
\hline
\end{tabular}

a. Dependent Variable: Students' Attitude

From the results in table 8, the unstandardized regression coefficients (B), indicate how much the dependent variable (students' attitudes towards chemistry) varies with an independent variable, when all other independent variables are held constant. Thus, the higher the B-value the greater the influence the independent variable has on the dependent variable. Teacher characteristics with an unstandardized regression coefficient (B) value of 1.058 and a standardized regression coefficient (Beta) value of 0.844 were reported to be the most significant in influencing students' attitudes towards chemistry. This means that a one-unit increase in teacher characteristics would yield a 1.058-unit increase in the predicted students' attitude towards chemistry. Similarly, for the standardized coefficient (Beta), a one standard deviation increase in teacher characteristics would yield a 0.844 standard deviation increase in the predicted students' attitude towards chemistry. Students' career interest with an unstandardized regression coefficient (B) value of -0.005 and a standardized regression coefficient (Beta) value of -0.004 was reported to be the third most significant in influencing students' attitudes towards chemistry. This means that a one-unit decrease in students' career interest would yield a 0.005-unit increase in the predicted students' attitude towards chemistry. Similarly, for the standardized coefficient (Beta), a one standard deviation decrease in students' career interest would yield a 0.004 standard deviation increase in the predicted students' attitude towards chemistry. Peer influence with an unstandardized regression coefficient (B) value of 0.004 and a standardized regression coefficient (Beta) value of 0.002 was reported to be the least significant in influencing students' attitudes towards chemistry. This means that a one-unit increase in peer influence would yield a 0.004-unit increase in the predicted students' attitude towards chemistry. Similarly, for the standardized coefficient (Beta), a one standard deviation increase in peer influence would yield a 0.002 standard deviation increase in the predicted students' attitude towards chemistry.

\section{Concluding Remarks}

The study investigated the influence of selected social factors on the students' attitude towards Chemistry in Nyamaiya division, Kenya. The results reported a strong positive correlation between teacher characteristics and students' attitudes towards chemistry, that is, as positive teacher characteristics increase, the students' positive attitudes towards chemistry also increase. Teachers who are highly motivating while delivering subject content and who are easily approachable help their students develop positive attitudes towards chemistry. The results reported no correlation between students' career interest, peer influence and students' attitudes towards chemistry; hence, students' career interest had no influence on the students' attitudes towards chemistry. The study recommended that the Ministry of Education in conjunction with schools should make deliberate efforts to offer seminars/workshops to teacher counsellors' career masters, directors of studies and head teachers. This will assist them obtain the necessary competencies needed for guiding and counselling both teachers and the students, more so on the importance of developing positive attitudes. Moreover, the Ministry of Education should develop in - service programmes and refresher courses for teachers that emphasize the need to adopt creative and motivating methods of teaching and the importance of being available to the students. 


\section{References}

Adesoji, F.A. (2008). Managing students' attitude towards science through problem - solving instructional strategy. Anthropologist, 10(1), 21-24.

Bandura, A. (1986). Social foundations of thought and action. Englewood Cliffs, NJ: Prentice-Hall.

Barchok, K.H., Too, J.K., \& Ngeno, K.J.(2013). Effect of collaborative concept mapping teaching strategy on students' attitudes towards chemistry in selected secondary schools in Kenya. Asian Journal of Social Sciences \& Humanities, (2)2,530-541.

Barchok, K.H., Too, J.K., \& Ngeno, K.J.(2013). Effect of collaborative concept mapping teaching strategy on students' attitudes towards chemistry in selected secondary schools in Kenya. Asian Journal of Social Sciences \& Humanities, (2)2,530-541.

Borg, W. R. \& Gall, M. D. (1989). Education Research: An Introduction. 4th ed. New York: Longman.

Breakwell, M.G. (2012). Gender, parental and peer influences upon science attitudes and activities. Public Understanding of Science, $1(2), 1-14$.

Cheung, D. (2009). Students' attitudes toward chemistry lessons. The Interaction effect between grade level and gender. Retrieved January 2, 2013, from http://dx.doi.org/10.1007/s11165-007-9075-4

Etherington, M. A. (2008). How girls' achievements in school art are undermined by boys' rejection of the subject: An investigation into gendered attitudes towards art and design education or why schoolboys drop art. Paper presented at the British Educational Research Association Annual Conference, Heriot-Watt University, Edinburgh, 3-6 September 2008. Retrieved August 28, 2013 from http://www.uel.ac.uk/cass/staff/margaretetherington/

Jegede, S.A. (2007). Students' anxiety towards the learning of chemistry in some Nigerian secondary schools. Educational Research and Review, 2(7), 193-197.

Johnson, W. (2012). Social learning theory strengths and weaknesses. Retrieved August 8, 2013 from http://www.ehow.com/list_ 6592126_social-learning-theory-strengths-weaknesses.html

Kan, A. \& Akba, A. (2006). Affective factors that influence chemistry achievement (attitude and self efficacy) and the power of these factors to predict chemistry achievement. Journal of Turkish Science Education, (3)1, 76-86.

Kelly, A. (1998). The customer is always right: Girls' and boys' reactions to science lessons. School Science Review, 69(249), $662-676$.

Kerlinger, F.N. (2000). Foundations of behavioural research. Delhi:ss. Chhbra.

Kosgei, A., Mise, J. K., Odera, O. \& Ayugi, M. E. (2013). Influence of teacher characteristics on students' academic achievement among secondary schools. Journal of Education and Practice, (4)3, 76-83.

Kususanto, P., Fui, C.S. \& Hooi, L.L., (2012). Teachers' expectancy and students' attitude towards science. Journal of Education and Learning, (6)2, 38-49.

Majeed, A. (2010). Peer group effects on academic achievement. Retrieved September 1, 2013 from http://www.scribd.com/doc /26716720/Peer-Effects-on-Academic-Achievement.

McLeod, S. A. (2011). Albert Bandura -Social Learning Theory. Simply Psychology, 63(1), 575-582.

Muellerleile, J. (2005). Attitude versus aptitude. Retrieved January 2, 2013, from http://www.4vqp.com/images/062305_Attitude vs. Aptitude.pdf

Mukala, J. M. (2012). Peer versus parental conformity among adolescents in secondary schools in Kitui District, Kenya. Unpublished Master's Thesis. Kenyatta University.

Mukama, E. (2010). Peer Group Influence, Alcohol Consumption, and Secondary School Students' Attitudes towards School. Unpublished Thesis of Master of Arts in Counselling of Makerere University, Kampala.

Okorodudu, G.N.(2013). Peer pressure and socioeconomic status as predictors of student's attitude to examination malpractice in Nigeria. International Journal of Education, 5(1), 36-52.

Olusola, O.O. \& Rotimi, C.O. (2012). Attitudes of Students towards the study of Physics in college of education Ikere Ekiti, Ekiti State, Nigeria. American International Journal of Contemporary Research (2)12, 86-90.

Oskamp, S., and Schultz, P. W. (2005). Attitudes and opinions (3rd Ed.). Mahwah, NJ: Lawrence Erlbaum Associates.

Thurstone, L. L. (1931). The measurement of social attitudes. Journal of Abnormal and Social Psychology 29(3), 32-66.

Udoukpong, B. E., Emah, I. E., Umoren, S. E. (2012). Student Attitudes, Parental Influence and Career Aspirations in Academic Achievement in Entrepreneurial Curriculum. Academic Research International (2)1, 527-536.

Usman, I.A.(2000). Relationship between students' performance in practical activities and their academic achievement in integrated science using NISTEP mode of teaching. The Journal of International Social Research, 45, 102-147.

Wells, C. S. \& Wollack, J. A. (2003). An instructor's guide to understanding test reliability. Retrieved August 16, 2013 from http://testing.wisc.edu/Reliability.pdfS

Woldeamanuel, M., Atagana, H. \& Engida, T. (2013). Students' anxiety towards the learning of chemistry in some Ethiopian universities. The African Journal of Chemical Education, 3 (2), 28-39. 